\title{
Correction to: External Geometry of Submanifolds in Conformal Kenmotsu Manifolds
}

\section{Roghayeh Abdi $^{1} \cdot$ Esmaiel Abedi ${ }^{1}$}

Published online: 13 November 2018

(c) Iranian Mathematical Society 2018

\section{Correction to: Bulletin of the Iranian Mathematical Society https://doi.org/10.1007/s41980-018-0082-1}

In the original publication of this article, the second author Esmaiel Abedi was inadvertently not mentioned. Now both authors are correctly listed.

The original article has been corrected.

The original article can be found online at https://doi.org/10.1007/s41980-018-0082-1.

$凶$ Roghayeh Abdi

rabdi@azaruniv.ac.ir

Esmaiel Abedi

esabedi@azaruniv.ac.ir

1 Department of Mathematics, Azarbaijan shahid Madani University, Tabriz 53751 71379, Iran 